\title{
In This Issue: Pragmatic Approaches to Population and Clinical Problems
}

\author{
Kurt C. Stange, MD, PbD, Editor \\ Ann Fam Med 2016;14:298-299. doi: 10.1370/afm.1964.
}

$\mathrm{T}$ This issue of Annals combines high-level population views with pragmatic, on-the-ground strategies for challenging problems.

Mainous and colleagues examine population trends over more than 2 decades in prediabetes in nonobese people. They find that one-third of non-obese people have diabetes, and this is not associated with abdominal obesity. ${ }^{1}$ We tend to think that the obesity epidemic is driving the epidemic in diabetes, and that abdominal obesity is a particularly good marker of those at risk. The finding that one-third of non-obese people have prediabetes is a shocking wake up call to treat this as a societal as well as a clinical problem.

Another population study examines the possibility that something as simple and practical as drinking enough water might be associated with reduced risk of diabetes. Chang and colleagues find that even adjusting for a number of potential confounding factors, a urine marker of inadequate hydration is associated with both higher body mass index and obesity. ${ }^{2}$ Although this population-level association doesn't prove causation, it raises the possibility that drinking more water could be part of a societal solution to the obesity problem.

A pragmatic intervention to reduce weight and increase physical activity in obese, sedentary patients seen in primary care is tested in a clinical trial by Eaton et al, and featured in this issue's Annals Journal Club. ${ }^{3}$ The authors find that an enhanced intervention has its peak effect at 12 months, with waning effects at 24 months. ${ }^{4}$

A population-based cohort study in 29 primary care practices finds that among people aged 80 years and older, sense of coherence is prospectively associated with lower mortality and less functional decline, even when controlling for multimorbity, depression, cognition, disability, and sociodemographics. ${ }^{5}$ The concept of sense of coherence has been appealing to clinicians ever since it was advanced by Antonovsky as part of his salutogenic approach to explaining why some people become ill under stress while others stay healthy. ${ }^{6}$ This study shows the great relevance of sense of coherence to caring for older patients in primary care.
To inform concerns about the future adequacy of the primary care workforce, a population study examines variation in retirement age of primary care physicians. The average retirement age of about 65 years varies little by specialty, practice location, or gender, indicating that demographic and specialty mix changes are unlikely to materially affect workforce numbers. ${ }^{7}$

Several studies in this issue address novel approaches to child health care.

A pragmatic clinical study by Hay et al examines urine samples from thousands of children to develop a clinical decision rule for diagnosing urinary tract infections in young children. They find that a decision rule based on signs and symptoms is superior to clinician diagnosis, and that urine dipstick results add further diagnostic value. ${ }^{8}$

A study of family physicians' care of mothers during their children's well-care visits identifies child visits as a ripe opportunity for interconception care of mothers in order to reduce maternal risk factors for subsequent adverse birth and maternal outcomes. ${ }^{9}$

A research brief uses an intriguing new populationassessment method, Google Trends, to evaluate an old observation-that ankle swelling seems to be more common during the summer. It turns out Internet searches for information on ankle swelling are highest in mid-summer, with seasonality explaining $86 \%$ of the search volume variability. ${ }^{10}$

A methodology study explicates the value of using best-worst scaling surveys to assess patients' individual priorities. In an application identifying the most and least salient influences on homeless women getting Pap smear tests, the authors discover that the availability of support for issues beyond health is very important to women seeking Pap testing. ${ }^{11}$

Another methodology study finds that a pragmatic approach using 2 different tools for estimating male osteoporosis risk can be helpful—using the MORES tool to identify men for DXA scanning, and the FRAX tool to guide treatment decisions. ${ }^{12}$

A methodology study by Mills et al shows how to 
use concept mapping to engage patients in improvement in primary care practice. ${ }^{13}$

In an era in which clinicians are drowning in clerical work, an essay by Solimeo and colleagues, based on their research with teams, makes a strong case for hiring and empowering clerks. Clerical staff who use clerical tasks as pathways to investing in long-term personal relationships can foster trust in the patient-centered medical home and the larger health care organization. ${ }^{14}$

Finally, an insightful medical student, observing and reflecting on a teacher and role model, shows the benefits of giving attention first to the person, and then to the patient and clinical picture. ${ }^{15}$

We welcome your reflections at http://www.Ann FamMed.org.

\section{References}

1. Mainous A, Tanner R, Jo A, Anton S. Prevalence of prediabetes and abdominal obesity among healthy-weight adults: 18-year trend. Ann Fam Med. 2016;14(4):304-310.

2. Chang T, Ravi N, Plegue M, Sonneville K, Davis M. Inadequate hydration, BMI, and obesity among US adults: NHANES 20092012. Ann Fam Med. 2016;14(4):320-324.

3. Romano M. A randomized clinical trial of a tailored lifestyle intervention for obese, sedentary, primary care patients. Ann Fam Med. 2016;14(4):iii

4. Eaton C, Hartman S, Perzanowski E, et al. A randomized clinical trial of a tailored lifestyle intervention for obese, sedentary, primary care patients. Ann Fam Med. 2016;14(4):311-319.

5. Boeckxstaens $P$, Vaes $B$, De Sutter $A$, et al. A high sense of coherence as protection against adverse health outcomes in patients aged 80 years and older. Ann Fam Med. 2016;14(4):337-343.
6. Antonovsky A. Unraveling The Mystery of Health - How People Manage Stress and Stay Well. San Francisco, CA: Jossey-Bass Publishers; 1987.

7. Petterson S, Rayburn W, Liaw W. When do primary care physicians retire? Implications for workforce projections. Ann Fam Med. 2016;14(4):344-349.

8. Hay A, Sterne J, Hood K, et al. Improving the diagnosis and treatment of urinary tract infection in young children in primary care: results from the DUTY prospective diagnostic cohort study. Ann Fam Med. 2016;14(4):325-336.

9. Rosener S, Barr W, Frayne D, Barash J, Gross M, Bennett I. Interconception care for mothers during well-child visits with family physicians: an IMPLICIT network study. Ann Fam Med. 2016;14(4):350-355.

10. Garrison S, Allan G, Korownyk C, et al. Seasonality of ankle swelling: population symptom reporting using Google Trends. Ann Fam Med. 2016;14(4):356-358.

11. Wittenberg E, Bharel M, Bridges J, Ward Z, Weinreb L. Using bestworst scaling to understand patient priorities: a case example of Papanicolaou tests for homeless women. Ann Fam Med. 2016;14(4): 359-364.

12. Cass A, Shepherd A, Asirot R, Mahajan M, Nizami M. Comparison of the Male Osteoporosis Risk Estimation Score (MORES) with FRAX in identifying men at risk for osteoporosis. Ann Fam Med. 2016;14 (4):365-369.

13. Mills G, LaNoue M, Cunningham A, Sharbaugh A. Concept mapping as a method to engage patients in clinical quality improvement. Ann Fam Med. 2016;14(4):370-376.

14. Solimeo S, Stewart G, Rosenthal G. The critical role of clerks in the patient-centered medical home. Ann Fam Med. 2016;14(4):377-379.

15. Karan A. A dance with Mrs Chan. Ann Fam Med. 2016;14(4):380-381. 